Proceedings

\title{
Fatty Acid and Sterol Profile of Nutmeg (Myristica fragrans) and Star Anise (Illicium verum) Extracted Using Three Different Methods ${ }^{\dagger}$
}

\author{
Marko Obranović 1,*, Joanna Bryś ${ }^{2}$, Maja Repajić ${ }^{1}$, Sandra Balbino ${ }^{1}$, Dubravka Škevin ${ }^{1}$, Andrzej Bryś ${ }^{3}$, \\ Petra Tonković ${ }^{1}$, Ana Marija Medved ${ }^{1}$, Verica Dragović Uzelac ${ }^{1}$ and Klara Kraljić ${ }^{1}$
}

Citation: Obranović, M.; Bryś, J.; Repajić, M.; Balbino, S.; Škevin, D.; Bryś, A.; Tonković, P.; Medved, A.M.; Uzelac, V.D.; Kraljić, K. Fatty Acid and Sterol Profile of Nutmeg (Myristica fragrans) and Star Anise (Illicium verum) Extracted by Three Different Methods. Proceedings 2021, 70, 33. https://doi.org/10.3390/ foods_2020-07687

Published: 9 November 2020

Publisher's Note: MDPI stays neutral with regard to jurisdictional claims in published maps and institutional affiliations.

Copyright: $\odot 2020$ by the authors. Licensee MDPI, Basel, Switzerland. This article is an open access article distributed under the terms and conditions of the Creative Commons Attribution (CC BY) license (http://creativecommons.org/licenses/by/4.0/).
1 Department of Food Engineering, Faculty of Food Technology and Biotechnology, University of Zagreb, Pierottijeva Str. 6, 10000 Zagreb, Croatia; maja.repajic@pbf.unizg.hr (M.R.); snedjer@pbf.hr (S.B.); dskevin@pbf.hr (D.Š.); petra.tonkovic@pbf.hr (P.T.); anamarijam@outlook.com (A.M.M.); vdragov@pbf.hr (V.D.U.); kkraljic@pbf.hr (K.K.)

2 Department of Chemistry, Institute of Food Science, Warsaw University of Life Sciences, Nowoursynowska St. 159c, 02-787 Warsaw, Poland; joanna_brys@sggw.edu.pl

3 Department of Fundamental Engineering, Institute of Mechanical Engineering and Energetics, Warsaw University of Life Sciences, Nowoursynowska St. 164, 02-776 Warsaw, Poland; andrzej_brys@sggw.edu.pl

* Correspondence: mobran@pbf.hr; Tel.: +385(0)95- 881- 7779

+ Presented at the 1st International Electronic Conference on Food Science and Functional Foods, 10-25 November 2020; Available online: https://foods_2020.sciforum.net/.

\begin{abstract}
Nutmeg (Myristica fragrans) and star anise (Illicium verum) are popular spices worldwide originally from South East part of Asia. In addition to as food condiment, they have been used extensively in traditional medicine and lately as a subject of research in the field of pharmacology and medical sciences. Most research has been done on the subject of essential oils, especially for star anise, while data on seed oil properties are much scarcer. The main problem in the oil extraction of nutmeg is the hardness of the nut, while, for star anise seed, it is relatively low oil yield (around $10 \%)$. This presents a significant problem for screw press production and demands different methods of extraction for better oil yield and quality. The aim of this research was to compare three different methods of oil extraction with $n$-hexane agitation-assisted extraction (AAE), Soxhlet extraction (SE), and accelerated solvent extraction (ASE) at 25 and $100^{\circ} \mathrm{C}$ and to compare the processes on the basis of invested time, oil yield, and fatty acid and sterol profile of the oils. The determination of fatty acid composition was carried out by GC-flame ionization detection (FID) analysis of fatty acid methyl esters, while the sterol composition was determined with GC-MS. The highest yield of oil was obtained using the Soxhlet method, while the best results combining time and yield were obtained with the ASE method at $100{ }^{\circ} \mathrm{C}$. The main fatty acid in star anise seed oil was lauric acid (average 62.30\%) with significant differences across extraction methods $(p<0.05)$, while myristic acid (average $75.69 \%$ ) was the most abundant in all samples of nutmeg oil. The main sterol in all samples was $\beta$-sitosterol.
\end{abstract}

Keywords: nutmeg; star anise; fatty acids; sterols; accelerated solvent extraction

\section{Introduction}

Nutmeg (Myristica fragrans) and star anise (Illicium verum) are native herbs from Southeast Asia which were traditionally used as spices, as a part of traditional medicine, or as a cosmetic ingredient. The main focus of previous scientific research done in this field was on essential/volatile oils, while there are little data regarding fixed oil properties. Nutmeg belongs to the family Myristicaceae and is a medium-sized, evergreen aromatic tree. Its seed (nutmeg) and its fleshy aril (mace) are used as spices. Guatemala, Indonesia, 
India, Nepal, Sri Lanka, Laos, and Bhutan produce more than $97 \%$ of global nutmeg [1]. The nutmeg tree is indigenous to the Banda Islands in the Moluccas in east Indonesia. Nutmeg butter, a fat derived from the seed, is used in perfumery, tobacco, and toothpaste. Medicinally, it is used to support digestion and to treat rheumatism. Myristica fragrans seed is also used for diarrhea, mouth sore, and insomnia [2]. Nutmeg contains an essential oil, a fixed oil, proteins, fats, starch, and mucilage. Yield of the essential oil is $5-15 \%$, and it has been the main focus of published scientific research. The intoxicating effects of the seeds have been assigned to the presence of myristin and elemicin in volatile oil, while myristin is responsible for most of its pharmacological effects [3]. Seeds also contain 25$50 \%$ fixed oils depending on the source [3-5] with dominant myristic, stearic, palmitic, oleic, linoleic, and lauric acids $[3,5,6]$. Significantly less research has been done on the sterol composition of nutmeg oil with dominant representatives in $\beta$-sitosterol and campesterol $[7,8]$. Star anise is an aromatic evergreen tree with red flowers and star fruits. It belongs to the family Schisandraceae and grows mainly in southern China and Vietnam. Its dried fruit is used as a spice, and it is very important in Chinese medicine where it is used to relieve vomiting, stomach pain, insomnia, skin inflammation, and rheumatic pain. It possesses antimicrobial, antiviral, and antioxidant properties, and the fruits are also referred to in Ayurveda, the traditional Indian system of medicine, for a variety of health problems [9]. Shikimic acid, which is used as a primary ingredient for antiviral drug Tamiflu (oseltamivir phosphate), is extracted from star anise. Oseltamivir is considered the only drug available which may reduce the severity of bird flu [9-11]. Other components of star anise which have been the focus of scientific research are essential oils, prenylated $\mathrm{C}_{6}-\mathrm{C}_{3}$ compounds, lignans, sesquiterpenes, and flavonoids [11]. Accelerated solvent extraction at elevated pressure (ASE) is a newer and more advanced extraction technique that has recently been increasingly used due to its many advantages. It is an automated method that represents an alternative to Soxhlet extraction with a shorter extraction time and less solvent usage. This extraction method involves the use of elevated pressure which keeps the solvent in a liquid state during extraction at higher temperatures and, thus, prevents it from evaporating. The application of elevated temperature increases the kinetic energy of molecules in the system, leading to an increase in the rate of chemical reactions, higher solubility, and higher diffusion rate of solutes in the solvent [12]. Furthermore, the ASE principle makes it possible to carry out extraction in several cycles, the purpose of which is to introduce a fresh solvent and, thus, maintain a favorable extraction balance [13]. The extraction is performed on a specially designed ASE device which contributes to the automation and ease of use of this extraction method. The aims of this present paper were (1) to give more detail information about the fatty acid and sterol composition of nutmeg and star anise seed oils, (2) to try to give alternative methods for oil extraction taking into account the hardness of nutmeg and low oil yield in star anise, and (3) to give some basis for further research of these seeds using ASE.

\section{Statistical Analysis}

The analysis of the studied samples was performed in triplicate. The results were presented as the mean \pm standard error (SE). The statistical analysis was carried out with ExcelStat 2020. One-way analysis of variance (ANOVA) was used to compare results between the studied seed oils. Differences between samples were examined using Tukey's test and were considered significant at $p<0.05$.

\section{Methods}

\subsection{Materials and Reagents}

Nutmeg (Myristica fragrans) and star anise (Illicium verum) were obtained from the local supplier of spices in Zagreb, Croatia. The nutmeg was from Thailand and the star anise was from Vietnam. All chemicals and solvents were of analytical grade and used without further purification. 


\subsection{Oil Extraction}

Soxhlet extraction-oil yield: Oil and moisture contents of the seeds were determined by using ISO methods 659 and $665[14,15]$. The data obtained were used to calculate oil yield, defined as the percentage of oil extracted by each process on a total oil extractable basis. Agitation-assisted extraction: Seeds were crushed and ground in Waring Blender WSG60E grinder into a fine powder. Extraction was performed by $n$-hexane. A sample mass of $4 \mathrm{~g}$ was extracted with $40 \mathrm{~mL}$ of $n$-hexane at room temperature using a table shaker. After $20 \mathrm{~min}$, the sample was centrifuged for $10 \mathrm{~min}$ at $5000 \mathrm{rpm}$. The supernatant was decanted and the pellet was returned to the flask and extracted two more times with $40 \mathrm{~mL}$ of hexane for $20 \mathrm{~min}$. Extracts were combined and evaporated to dryness at $60^{\circ} \mathrm{C}$ on a rotary evaporator and afterward purged under a stream of nitrogen to remove any residual solvent. Accelerated solvent extraction: Accelerated solvent extraction (ASE) was applied for oil extraction from nutmeg and star anise seeds. The procedure was conducted on a Dionex ${ }^{\mathrm{TM}}$ ASE ${ }^{\mathrm{TM}} 350$ Accelerated Solvent Extractor (Thermo Fisher Scientific Inc., Sunnyvale, CA, USA) using $n$-hexane as the extraction solvent. A mixture of sample ( $8 \mathrm{~g}$ ) and diatomaceous earth $(0.5 \mathrm{~g})$ was placed into $34 \mathrm{~mL}$ stainless-steel cells fitted with two cellulose filters at the bottom of the cells. Extraction conditions were set according to the method described by [16], slightly modified: temperature at 25 and $100{ }^{\circ} \mathrm{C}$, static extraction time of $10 \mathrm{~min}$ with six extraction cycles, constant pressure of $10.34 \mathrm{MPa}, 30 \mathrm{~s}$ of purge with nitrogen, and 50\% flushing. Obtained extracts were collected in $250 \mathrm{~mL}$ glass vessels with Teflon septa, evaporated at $60{ }^{\circ} \mathrm{C}$ under vacuum and afterward purged under a stream of nitrogen to remove any residual solvent.

\subsection{Fatty Acid and Sterol Composition}

Fatty acid composition was determined by using gas chromatography. Fatty acid methyl esters $(1 \mu \mathrm{L})$, prepared using ISO method 12966-2 [17], were injected into a GC equipped with a flame ionization detector (FID). Fatty acid methyl esters (FAMEs) were separated on a TRACE TR-FAME capillary column $(30 \mathrm{~m} \times 0.22 \mathrm{~mm} \times 0.25 \mu \mathrm{m})$ using a stationary phase of $70 \%$ cyanopropyl polysilphenylene-siloxane (Thermo Scientific, Waltham, MA, USA). Helium was used as the carrier gas at a $0.7 \mathrm{~mL} / \mathrm{min}$ flow rate. The temperature of the injector was set at $250{ }^{\circ} \mathrm{C}$ and that of the detector was set at $280{ }^{\circ} \mathrm{C}$. The temperature of the oven was programmed to increase $4{ }^{\circ} \mathrm{C} / \mathrm{min}$ from an initial value of 120 to $160^{\circ} \mathrm{C}$, and then at $10^{\circ} \mathrm{C} / \mathrm{min}$ to $190^{\circ} \mathrm{C}$, where it was held for $10 \mathrm{~min}$. The split ratio was 75:1. Fatty acid methyl ester peaks were identified by comparing their retention times with those of FAME standards (C8-C22). Sterol composition was determined by using the standard ISO method [18]. Nonpolar extracts were spiked with $\alpha$-cholestanol as an internal standard and saponified by potassium hydroxide. Unsaponified fractions were eluted by diethyl ether on an aluminum oxide-filled glass column and then converted to trimethylsilyl derivates. Individual components were separated and determined on the ATI Unicam 610 (Boston, MA, USA) gas chromatograph equipped with a flame ionization detector. Gas chromatography column Agilent DB-17 $(30 \mathrm{~m} \times 0.32 \mathrm{~mm}$, film thickness $0.25 \mu \mathrm{m}$; Santa Clara, CA, USA) was heated from 180 to $270{ }^{\circ} \mathrm{C}$ at a rate of $6{ }^{\circ} \mathrm{C} / \mathrm{min}$ and then kept at $270{ }^{\circ} \mathrm{C}$ for $30 \mathrm{~min}$. The helium flow rate was set to $1.5 \mathrm{~mL} / \mathrm{min}$, a split ratio of $13.3: 1$ was used, and $1 \mu \mathrm{L}$ of sample was injected. The injector was kept at $290^{\circ} \mathrm{C}$ and the detector was kept at $250^{\circ} \mathrm{C}$.

\section{Results and Discussion}

\subsection{Oil Extraction Yield}

Oils used in this study were extracted from seeds using $n$-hexane and three different methods. Every method has its advantages and disadvantages, whereby SE is done over a longer time period $(8 \mathrm{~h})$, ASE is done on a significantly shorter timescale under elevated pressure and with much less solvent usage, and AAE avoids any application of higher temperature during extraction on a timescale more similar to ASE. Average results for the 
oil yield of nutmeg and star anise and average yield of oil depending on the extraction method are presented on Figure 1 . The average yield of oil in nutmeg was $24.46 \%$ with the highest value obtained with AAE at $26.90 \%$ and lowest with ASE25 at 22.10\%. These values are lower or at the lower limits of previously published papers at $25-50 \%$ [3-5]. Unfortunately, all of the citied papers are review papers which referred to much older research from 1992 [3,4] and a book published in 1981 [5]. Original research published in 1987 gave a similar result of $30 \%$ of oil [8]. There is a need for much more detailed and contemporary research in this scientific field. Published research in English on the oil quantity from star anise is even scarcer, with most of the work published in Chinese with short abstracts in English through the China National Knowledge Infrastructure (CNKI). The average oil yield for star anise was $10.53 \%$ with the lowest value at $9.55 \%$ obtained using AAE and the highest at $11.95 \%$ obtained using ASE100. In their research on $\mathrm{CO}_{2}$ oil extraction optimization from star anise, Li et al. [19] published a span between $6.80 \%$ and $23.72 \%$ of oil depending on extraction conditions.

The highest yield in oil extraction was obtained with ASE100 and the lowest yield was obtained with ASE25 (Figure 1). It is evident that the influence of elevated pressure alone (ASE25) does not result in satisfactory utilization and that the combination of elevated temperatures and pressures is key to more efficient ASE. According to the above, for future research on the extraction of oil from spice seeds with ASE, it is important to further optimize the extraction conditions using temperatures $>100{ }^{\circ} \mathrm{C}$, as well as other solvents, to increase efficiency or recovery.

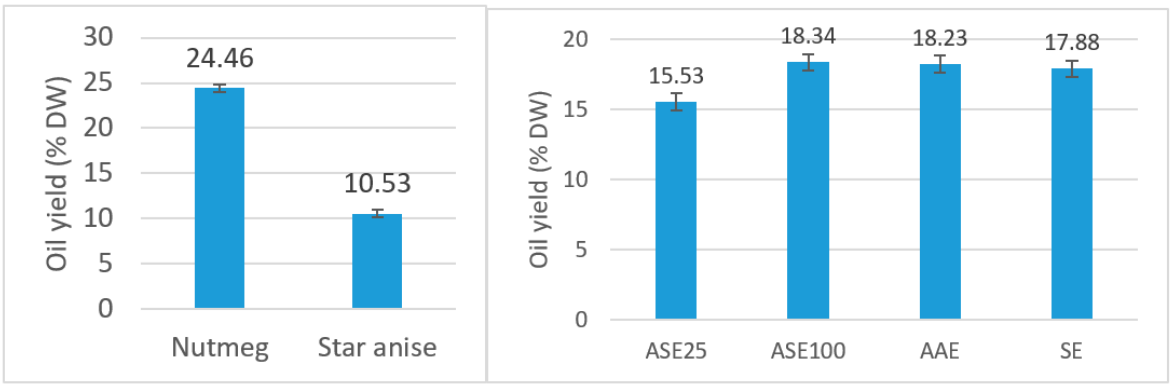

Figure 1. Oil yield in samples and average yield obtained using different extraction methods $(p<0.05)$. Results are shown as the mean \pm standard error.

\subsection{Fatty Acid Composition}

The fatty acid compositions of analyzed samples are presented in Table 1. Eight different fatty acids were identified in nutmeg oil. The dominant fatty acid in all nutmeg oil samples was myristic acid C14:0 with an average of $75.69 \%$, which is similar to other research with $79.20 \%$ [8]. Together with oleic acid (C18:1n9-13.00\%) and palmitic acid (C16:0-7.89\%), it constituted more than $96 \%$ of total fatty acids. Kuete [3], in his chapter on "Chemistry of Myristica fragrans", cited myristic, stearic, palmitic, oleic, linoleic, and lauric acids as the main components. Contrary to his findings, the presented results had significantly lower lauric acid quantities. Abdurasheed and Janardanan [4] in their research also had a higher value of lauric acid $(8.00 \%)$ but much lower value of myristic fatty acid $(55.10 \%)$. The fatty acid composition of seeds depends on their genetic characteristics, but the latitude and climatic conditions of cultivation also have a strong influence on the biosynthesis of fatty acids [20]. The dominant fatty acid in star anise oil was lauric acid with an average of $62.30 \%$. Other significant components included linoleic acid $(13.33 \%)$, oleic acid $(12.57 \%)$, and palmitic acid $(8.43 \%)$. Together, they constituted more than $96 \%$ of all fatty acids. Contrary to results published by Li et al. [19], presenting $71 \%$ unsaturated fatty acids, our results showed an average of $72.57 \%$ saturated fatty acids, which could be explained by the methods of extraction having a significant effect only on lauric acid and a few smaller components ( $p \leq 0.05$; Table 2$)$. 
Table 1. Influence of seed type and extraction method on composition and content (\%) of fatty acids in nutmeg and star anise seed oils

\begin{tabular}{|c|c|c|c|c|c|c|c|c|c|c|c|c|c|c|}
\hline & SFA & MUFA & PUFA & C12:0 & C14:0 & C14:1 & C16:0 & C16:1 & C17:0 & C18:0 & C18:1n9 & C18:2n6 & C18:3n6 & C20:0 \\
\hline Type of seed & $p<0.01^{*}$ & $p<0.01^{*}$ & $p<0.01^{*}$ & $p<0.01^{*}$ & $p<0.01^{*}$ & $p<0.01^{*}$ & $p<0.01^{*}$ & $p=0.09$ & $p<0.01^{*}$ & $p<0.01^{*}$ & $p=0.13$ & $p<0.01^{*}$ & $p<0.01^{*}$ & $p=0.32$ \\
\hline Nutmeg & $85.59 \pm 0.42$ & $3.12 \pm 0.24$ & $1.29 \pm 0.19$ & $0.00 \pm 0.41 \mathrm{a}$ & $75.69 \pm 0.19$ & $0.00 \pm 0.04$ & $7.89 \pm 0.12 \mathrm{a}$ & $.12 \pm 0.11$ & $0.84 \pm 0.02 \mathrm{a}$ & $1.00 \pm 0.04$ & $13.00 \pm 0.12$ & $1.15 \pm 0.19$ & $0.15 \pm 0.00$ a & $.17 \pm 0.02^{a}$ \\
\hline Star anise & & & & & & & & & & & & & & \\
\hline Extraction method & $p=0.28$ & $p=0.18$ & $p=0.08$ & $p<0.01^{*}$ & $p=0.05$ & $p<0.01^{*}$ & $p=0.31$ & $p<0.01^{*}$ & $p=0.27$ & $p=0.25$ & $p=0.51$ & $p=0.08$ & $p<0.01^{*}$ & $p=0.08$ \\
\hline ASE25 & $79.27 \pm 0.59$ & $3.61+0.34$ & $12+026$ & & & $043+054$ & $8.02 \pm 0.17 \mathrm{a}$ & & $0.39+0.02 a$ & $.28 \pm 0.05$ & $13.08 \pm 0.28$ & $6.97 \pm 0.27$ & 0.15 & $0.18 \pm 0.03^{a}$ \\
\hline ASE100 & 79.81 & & $\delta 2 \pm 1$ & & \pm 0 & $.63 \pm$ & & & & & $2.60 \pm$ & 6.72 & 0.1 & 0.03 a \\
\hline AAE & $79.12 \pm 0.5$ & & $.75 \pm 0.2$ & & $8.63 \pm 0$ & & $8.19 \pm 0$ & & & & 2.57 & & & 0.03 a \\
\hline $\mathrm{SE}$ & $78.12 \pm 0.59$ & $4.23 \pm 0.34$ & $.66 \pm 0.26$ & $9.99 \pm 0.58$ & $7.69 \pm 0.27$ & $0.62 \pm 0.54$ & $8.43 \pm 0.17 \mathrm{a}$ & $.73 \pm 0.16$ & $0.43 \pm 0.02 \mathrm{a}$ & & $12.88 \pm 0$ & $7.59 \pm 0.2$ & & $.19 \pm 0.03 a$ \\
\hline
\end{tabular}

$\mathrm{ASE}=$ accelerated solvent extraction (at 25 and $100^{\circ} \mathrm{C}$ ); AAE = agitation-assisted extraction; SE = Soxhlet extraction; SFA = saturated fatty acid; MUFA monounsaturated fatty acid; PUFA = polyunsaturated fatty acid. Results are shown as the mean \pm standard error. * Statistically significant variation at $p \leq 0.05$. The values within the columns marked with different letters differ statistically at $p \leq 0.05$

Table 2. Influence of seed type and extraction method on composition and content (mg/100 g) of sterols in nutmeg and star anise seed oils.

\begin{tabular}{|c|c|c|c|c|c|c|c|c|c|c|c|}
\hline & \multicolumn{11}{|c|}{ CampesterolCampestanolStigmasterol $\beta$-Sitosterol Sitostanol $\triangle 5$-Avenasterc } \\
\hline Type of seed & $p<0.01 *$ & $p<0.01^{*}$ & $p=0.85$ & $p<0.01^{*}$ & $p=0.34$ & $p<0.01^{*}$ & $p<0.01^{*}$ & $p=0.05^{*}$ & $p<0.01^{*}$ & $p=0.03^{*}$ & $p<0.01^{*}$ \\
\hline Nutmeg & $131.5^{\mathrm{a}} \pm 12.8$ & $0.0^{\mathrm{b}} \pm 0.6$ & $15.3^{\mathrm{a}} \pm 0.8$ & $214.8^{\mathrm{b}} \pm 8.2$ & $0.1 \mathrm{a} \pm 0.0$ & $32.9^{a} \pm 1.1$ & $0.0^{\mathrm{b}} \pm 0.2$ & $0.0^{\mathrm{b}} \pm 0.8$ & $4.7^{\mathrm{a}} \pm 1.0$ & $0.0^{\mathrm{b}} \pm 0.3$ & $399.2^{a} \pm 14.6$ \\
\hline Star anise & $47.1^{\mathrm{b}} \pm 12.8$ & $4.1^{\mathrm{a}} \pm 0.6$ & $15.5^{\mathrm{a}} \pm 0.8$ & $256.9 \mathrm{a} \pm 8.2$ & $0.0^{\mathrm{a}} \pm 0.0$ & $0.8^{\mathrm{b}} \pm 1.1$ & $5.5^{\mathrm{a}} \pm 0.2$ & $2.6^{\mathrm{a}} \pm 0.8$ & $0.0^{\mathrm{b}} \pm 1.0$ & $1.1^{\mathrm{a}} \pm 0.3$ & $333.6^{\mathrm{b}} \pm 14.6$ \\
\hline Extraction method & d $p=0.02 *$ & $p=0.03 *$ & $p=0.05$ & $p=0.14$ & $p=0.02$ * & $p=0.43$ & $p=0.22$ & $p=0.08$ & $p=0.05$ & $p=0.05$ & $p=0.05^{*}$ \\
\hline ASE25 & $135.8^{\mathrm{a}} \pm 18.1$ & $2.1 \mathrm{ab} \pm 0.9$ & $16.1^{a} \pm 1.1$ & $250.5 \mathrm{ab} \pm 11.6$ & $60.1^{\mathrm{a}} \pm 0.1$ & $18.1^{\mathrm{a}} \pm 1.5$ & $2.7 \mathrm{a} \pm 0.2$ & $0.0^{\mathrm{a}} \pm 1.2$ & $5.0^{\mathrm{a}}=$ & $0.0^{\mathrm{a}} \pm 0.4$ & $430.4^{a} \pm 20.6$ \\
\hline ASE100 & $102.0 \mathrm{ab} \pm 18.1$ & $0.0^{\mathrm{b}} \pm 0.9$ & $17.2^{\mathrm{a}} \pm 1.1$ & $259.5 \mathrm{a} \pm 11.6$ & $0.0^{\mathrm{b}} \pm 0.1$ & $16.7 \mathrm{a} \pm 1.5$ & $3.0^{\mathrm{a}} \pm 0.2$ & $0.6^{\mathrm{a}} \pm 1.2$ & $4.3^{\mathrm{a}} \pm 1.4$ & $0.4^{\mathrm{a}} \pm 0.4$ & $403.6^{\mathrm{ab}} \pm 20.6$ \\
\hline AAE & $63.7 \mathrm{ab} \pm 18.1$ & $2.0 \mathrm{ab} \pm 0.9$ & $15.0^{a} \pm 1.1$ & $231.0 \mathrm{ab} \pm 11.6$ & $60.0^{b} \pm 0.1$ & $14.2^{\mathrm{a}} \pm 1.5$ & $3.1^{\mathrm{a}} \pm 0.2$ & $4.7^{\mathrm{a}} \pm 1.2$ & $0.0^{\mathrm{a}} \pm 1.4$ & $1.8^{\mathrm{a}} \pm 0.4$ & $335.3 b c \pm 20.6$ \\
\hline $\mathrm{SE}$ & $55.8^{\mathrm{b}} \pm 18.1$ & $4.0^{\mathrm{a}} \pm 0.9$ & $13.3^{\mathrm{a}} \pm 1.1$ & $202.4^{\mathrm{b}} \pm 11.6$ & $50.0^{b} \pm 0.1$ & $18.5^{\mathrm{a}} \pm 1.5$ & $2.2^{\mathrm{a}} \pm 0.2$ & $0.0^{\mathrm{a}} \pm 1.2$ & $0.0^{\mathrm{a}} \pm 1.4$ & $0.0^{\mathrm{a}} \pm 0.4$ & $296.3^{c} \pm 20.6$ \\
\hline
\end{tabular}

* Statistically significant variables at $p \leq 0.05$. Results are expressed as the mean \pm SE. Values in the same column with different letters are statistically different at $p \leq 0.05$ 


\subsection{Sterol Composition}

Results for sterol composition are presented in Table 2. The dominant sterol in all samples was $\beta$-sitosterol (average in nutmeg $=214.8 \mathrm{mg} / 100 \mathrm{~g}$ and average in star anise $=$ $256.9 \mathrm{mg} / 100 \mathrm{~g}$ ). Other significant sterols in nutmeg oil were campesterol and $\Delta 5$-avenasterol, while those in star anise oil were campesterol and stigmasterol. Higher values for total sterols were in nutmeg oil and oils extracted with ASE25 and ASE100. Moreau et al. [21] used ASE at 40 and $100{ }^{\circ} \mathrm{C}$ to extract the sterol fraction from maize and oats, and they found that applying a higher temperature increased its concentration in the extract.

\section{Conclusions}

Nutmeg and star anise seed oils present an interesting source of myristic and lauric fatty acids, while the application of ASE in their extraction is far more suitable at higher temperatures. In addition to a higher oil yield, it enhances sterol extraction by around $50 \%$.

Funding: This research received no external funding.

Institutional Review Board Statement: Not applicable.

Informed Consent Statement: Not applicable.

Data Availability Statement: Not applicable.

Acknowledgments: The authors would like to show their appreciation to laboratory technician Melisa Trputec for her assistance during the research.

\section{References}

1. Abdurrasheed, K.M.; Janardanan, C. Chemical composition of nutmeg and mace (Myristica fragrans Houtt.) from Tellicherry and Kannur regions, Kerala. J. Spices Aromat. Crop. 2009, 18, 108-110.

2. Al-Khatib, I.M.H.; Hanifa Moursi, S.A.; Mehdi, A.W.R.; Al-Shabibi, M.M. Gas-liquid chromatographic determination of fatty acids and sterols of selected Iraqi foods. J. Food Compos. Anal. 1987, 1, 59-64, doi:10.1016/0889-1575(87)90011-1.

3. Dinesha, R.; Thammannagowda, S.S.; Prabhu, M.S.L.; Madhu, C.S.; Srinivas, L. The antioxidant and DNA protectant activities of Star Anise (Illicium verum) aqueous extracts. J. Pharmacogn. Phytochem. 2014, 2, 98-103.

4. FAO [WWW Document]. 2020. Available online: http://www.fao.org/faostat/en/\#data/QC (accessed on 5 October 2020).

5. Hou, J.P.; Wu, H.; Wang, Y.; Weng, X.C. Isolation of some compounds from nutmeg and their antioxidant activities. Czech J. Food Sci. 2012, 30, 164-170, doi:10.17221/509/2010-cjfs.

6. ISO. Animal and Vegetable Fats and Oils-Gas Chromatography of Fatty Acid Methyl Esters - Part 2: Preparation of Methyl Esters of Fatty Acids [WWW Document]. 2017. ISO 12966-22017. Available online: https://www.iso.org/standard/72142.html (accessed on 6 October 2020).

7. ISO. Determination of Individual and Total Sterols Contents-Gas Chromatographic Method-Part 1: Animal and Vegetable Fats and Oils [WWW Document]. 2014. ISO 12228-12014. Available online: https://www.iso.org/standard/60248.html (accessed on 10 October 2020).

8. ISO. Oilseeds-Determination of oil content [WWW document] 2009. ISO 659:2009. Available online: https://www.iso.org/standard/43169.html (accessed on 10 October 2020).

9. ISO. Oilseeds-Determination of moisture and volatile matter content [WWW document] 2000. 665:2000. Available online: https://www.iso.org/standard/31099.html (accessed on 10 October 2020).

10. Jentzer, J.B.; Alignan, M.; Vaca-Garcia, C.; Rigal, L.; Vilarem, G. Response surface methodology to optimise Accelerated Solvent Extraction of steviol glycosides from Stevia rebaudiana Bertoni leaves. Food Chem. 2015, 166, 561-567, doi:10.1016/j.foodchem.2014.06.078.

11. Kuete, V. (Ed.) Myristica fragrans: A Review. In Medicinal Spices and Vegetables from Africa; Elsevier Inc.: Amsterdam, The Netherlands, 2017; pp. 497-512, doi:10.1016/B978-0-12-809286-6.00023-6.

12. Li, G.; Sun, Z.; Xia, L.; Shi, J.; Liu, Y.; Suo, Y.; You, J. Supercritical $\mathrm{CO}_{2}$ oil extraction from Chinese star anise seed and simultaneous compositional analysis using HPLC by fluorescence detection and online atmospheric CI-MS identification. J. Sci. Food Agric. 2010, 90, 1905-1913, doi:10.1002/jsfa.4031.

13. Linder, C.R. Adaptive evolution of seed oils in plants: Accounting for the biogeographic distribution of saturated and unsaturated fatty acids in seed oils. Am. Nat. 2000, 156, 442-458, doi:10.1086/303399.

14. Lohani, U.C.; Fallahi, P. Comparison of Ethyl Acetate with Hexane for Oil Extraction from Various Oilseeds. J. Am. Oil Chem. Soc. 2015, 743-754, doi:10.1007/s11746-015-2644-1. 
15. Manasa, V.; Vaishnav, S.R.; Tumaney, A.W. Physicochemical characterization and nutraceutical compounds of the selected spice fixed oils. J. Food Sci. Technol. 2020, doi:10.1007/s13197-020-04813-8.

16. Moreau, R.A.; Powell, M.J.; Singh, V. Pressurized Liquid Extraction of Polar and Nonpolar Lipids in Corn and Oats with Hexane, Methylene Chloride, Isopropanol, and Ethanol. JAOCS J. Am. Oil Chem. Soc. 2003, 80, 1063-1067, doi:10.1007/s11746-0030821-y.

17. Nagja, T.; Vimal, K.; Sanjeev, A. Myristica fragrans: A comprehensive review. Int. J. Pharm. Pharm. Sci. 2016, 8, 27-30.

18. Niyas, Z.; Variyar, P.S.; Gholap, A.S.; Sharma, A. Effect of $\gamma$-Irradiation on the Lipid Profile of Nutmeg (Myristica fragrans Houtt.). J. Agric. Food Chem. 2003, 51, 6502-6504, doi:10.1021/jf030313o.

19. Patra, J.K.; Das, G.; Bose, S.; Banerjee, S.; Vishnuprasad, C.N.; del Pilar Rodriguez-Torres, M.; Shin, H.S. Star anise (Illicium verum): Chemical compounds, antiviral properties, and clinical relevance. Phyther. Res. 2020, 34, 1248-1267, doi:10.1002/ptr.6614.

20. Sarker, M.A.M.; Sarker, S.D. Accelerated Solvent Extraction for Natural Products Isolation. In Natural Products Isolation; Human Press: Totowa, NJ, USA, 2012; pp. 75-87.

21. Wang, G.W.; Hu, W.T.; Huang, B.K.; Qin, L.P. Illicium verum: A review on its botany, traditional use, chemistry and pharmacology. J. Ethnopharmacol. 2011, 136, 10-20, doi:10.1016/j.jep.2011.04.051. 